\title{
A PAISAGEM URBANA E O CLIMA URBANO DE CIDADES DE MÉDIO PORTE DO CENTRO-OESTE BRASILEIRO, DOURADOS (MS) E RIO VERDE (GO)
}

\author{
Vladimir Aparecido dos Santos ${ }^{(a)}$, Charlei Aparecido da Silva ${ }^{(b)}$ \\ (a) Doutorando do Programa de Pós-Graduação em Geografia-PPGG/Faculdade de Ciencias Humanas-FCH, \\ Universidade Federal da Grande Dourados-UFGD, Email: vladimirvas@yahoo.com.br \\ (b) Professor Dr. do Programa de Pós-Graduação em Geografia-PPGG/Faculdade de Ciencias Humanas-FCH, \\ Universidade Federal da Grande Dourados-UFGD, Email: charleisilva@ufgd.edu
}

\section{Eixo: 3. Climatologia em diferentes níveis escalares: mudanças e variabilidades}

\begin{abstract}
Resumo
Este trabalho tem como base teórica o estudo da paisagem urbana e suas interações com a teoria Sistema Clima Urbano (SCU) de Monteiro(1976). Tem como proposição de pesquisa compreender as relações da paisagem urbana com o desencadeamento do clima urbano de cidades de médio porte da Região CentroOeste do Brasil, especificamente, as cidades de Dourados (MS) e Rio Verde (GO). E dessa forma objetiva-se apontar de forma classificatória local e regional dos tipos de tempo e climas, em consonância aos subsistemas Hidrometeórico, Termodinâmico e Físico-químico do SCU das cidades citadas. Avaliando assim os impactos da produção da paisagem urbana nas relações sociais no interior das cidades.
\end{abstract}

Palavras chave: paisagem urbana, clima urbano, Centro-Oeste.

\section{Introdução: aportes conceituais iniciais da paisagem}

A categoria paisagem se posiciona como uma proposta de interação de variáveis ambientais, interpretada como uma unidade complexa com variáreis inter-relacionada, analiticamente falando (FERREIRA, 2016).

A palavra "paisagem" remonta conceitos primitivos originalmente no período medieval. Nas línguas do romantismo, é relativa ao termo latimpagus(país), o qual utiliza sentido de lugar ou território. Já nas línguas germânicas, é originada da palavra land, com praticamente o mesmo significado, Hardt (2000).

A origem da palavra paisagem tem sua gênese etimológica no latim: pagus, que significa país, no sentido de setor territorial e de lugar. A partir desse significado derivam semelhanças em outras línguas como: paysage(em francês), paesaggio(em italiano) etc. O mesmo ocorre com as línguas germânicas: land, landschaft(alemão) landscape(inglês), landschap(holandês) etc. (FERREIRA, 2016, p. 49).

Mazzoni (2014) reforça indagando que o termo paisagem observa várias acepções e seu significado é variado ao longo do tempo, sendo que, sua conceituação mais genérica, é que a paisagem pode ser definida como uma porção do território com suas características próprias, e são os resultados da inter-relação entre os processos naturais e antropogênicos ao longo do tempo, porém, sem sombra de dúvidas, o termo paisagem tem referência ao modo em que as pessoas percebem o território. 
El término "Paisaje" es un concepto que fue incorporado al vocabulario técnico de la Geografía a principios del Siglo XIX, aunque su significado ha variado a lo largo del tiempo y reconoce hoy al menos dos acepciones. Conjuntamente con las diversas interpretaciones, el estudio del paisaje se aborda desde distintas concepciones filosóficas y con variados métodos. (MAZZONI, 2014, p. 51).

Para Ferreira (1986, p. 1247) a paisagem é apontada como "espaço de terreno que se abrange num lance de vista".

\begin{abstract}
"A concepção sobre a paisagem como uma totalidade dialética de base natural, foi desenvolvida principalmente na União Soviética, e posteriormente em outros países do mundo socialista. Duas condições permitiram o seu desenvolvimento: o uso do Marxismo Leninismo como doutrina oficial que privilegiava a análise dialética das totalidades e das interações dos fenômenos e a necessidade da construção socialista sustentada no planejamento centralizado, que precisava do conhecimento das unidades naturais integradas, para serem transformadas e dominadas". (FERREIRA, 2016, p. 49).
\end{abstract}

Ferreira (2016) interpretando Verdum (2012), o termo paisagem vem a sugerir duas formas distintas passível de entendimento, isto é, a visão objetiva e sua representação, a qual é baseada naquilo que a visão alcança, e dessa forma, a visão possibilita que se construa a noção de paisagem como uma espécie de mosaico relativamente ordenado de formas e cores. E assim, o alcance e os limites da visão nos dá a condição de estabelecer a noção de espaço da paisagem.

Existem dois contextos em que a paisagem é analisada: os espaços visuais, que podem ser natural ou antropizado, de lenta ou rápida evolução, respectivamente; e a percepção, representada pela composição de formas naturais e antrópicas; pelos valores de condições de visibilidade, qualidade e fragilidade da paisagem, assim como de potenciais para seu desenvolvimento visual; e pelas respostas sensitivas e psicológicas do observador. (BONAMETTI, 2010, p. 262).

Em 2000, Florência na Itália, o Conselho da Europa, firmando entre os países intervenientes o Convênio Europeu de Paisagem, estabeleceu-se o primeiro tratado internacional com a temática da paisagem, que é um marco normativo para a proteção, ordenação e gestão das paisagens. "En este tratado se define paisaje como una porción del territorio, tal y como es percibida por su población, siendo su aspecto el resultado de la acción y la interacción de factores naturales y humanos" (Consejo de Europa, 2000: art. 1a). Nestadefinição é necessáriodizer que se incorpora "cuatro dimensiones: física (porción del territorio), holística y temporal (el paisaje como resultado de la acción e interacción de fenómenos naturales y humanos -que se desarrollan a lo largo del tiempo-) y subjetivo-cultural (percepción que los habitantes tienen del paisaje)”, Mazzoni (2014, p. $56)$.

Hardt (2000) dialoga que a paisagem em conceito amplo pode ser interpretada como a combinação dinâmica de elementos naturais, a saber, os físico-químicos e biológicos, como também os antrópicos, de forma interrelacionada e interdependente, que em dado momento de tempo cronológico, espaço e momento social, formam um conjunto único e indissociável em equilíbrio ou não, que está em permanente evolução, promovendo a produção de percepções mentais e sensações estéticas como um "ecossistema visto".

Ainda,tende-se a classificar os componentes da paisagem em: 


\section{OS DESAFIOS DA GEOGRAFIA FÍSICA NA FRONTEIRA DO CONHECIMENTO \\ Instituto de Geociências - Unicamp \\ Campinas - SP \\ 28 de Junho à 02 de Julho de 2017}

de Geografia Física

a) ambientais: integrados por fatores fixos, móveis e mutáveis dos sistemas natural e cultural; o predomínio de componentes ambientais de cada um desses sistemas determina a tipologia de uma paisagem natural ou cultural, respectivamente;

b) estéticos/perceptivos: compostos por elementos visuais e composição paisagística (LITTON Jr, 1972; TEDESCHI, 1977, ESCRIBANO et alii, 1989); também podem ser percebidos na paisagem alguns elementos não visuais - sonoros, táteis, odoríficos e movimento, entre outros.(HARDT, 2000, p. 15)

Segue abaixoorganograma (figura 1) dos principais componentes da paisagem.

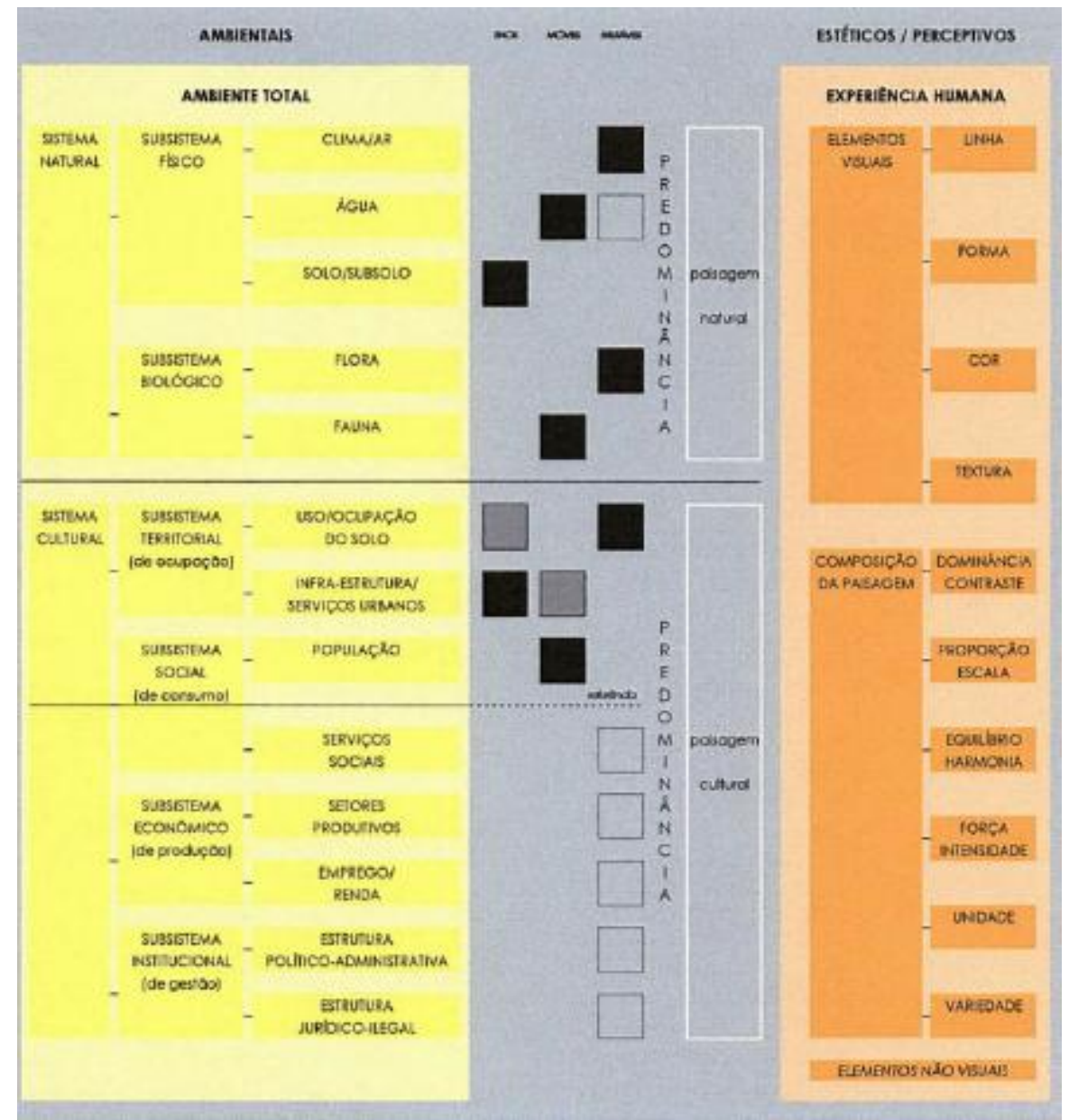

FIGURA 1 - Organograma dos principais componentes da Paisagem Fonte: HARDT (2000, p. 16)

Seguindo as afirmações de Forman \&Godron (1986) interpretadas por Hardt(2000, p.17-18), as paisagens podem ser classificadas como (figura 2):

a) natural, onde o resultado visual não apresenta impacto humano significativo;

b) manejada, onde o resultado visual tende à homogeneização pelo manejo de espécies nativas;

c) cultivada, onde o resultado visual tende à geometrização de formas, pela presença de mosaicos de áreas cultivadas e de ecossistemas naturais e manejados, além de aglomerados humanos;

d) suburbana, onde o resultado visual compreende mosaicos de parcelas menores e mais heterogêneas de áreas cultivadas e ocupações urbanas, especialmente;

e) urbana, onde o resultado visual compreende um forte conjunto de formas e volumes geométricos, podendo-se relacionar nesse contexto uma maior proporção de áreas impermeáveis em relação às tipologias anteriores. 
XVII Simpósio Brasileiro

de Geografia Fisica Aplicada

I Congresso Nacional

de Geografia Física

\section{OS DESAFIOS DA GEOGRAFIA FÍSICA NA FRONTEIRA DO CONHECIMENTO \\ Instituto de Geociências - Unicamp \\ Campinas - SP \\ 28 de Junho à 02 de Julho de 2017}

Porém, é preciso estudar "[...] não os componentes da natureza, mas as conexões entre eles; não se deve restringir à morfologia da paisagem e suas subdivisões de preferência, projetar-se para o estudo de sua dinâmica, estrutura funcional, conexões, etc.” Sotchava (1977, p. 2) apud Ferreira (2016, p. 55).

En cuanto a la clasificación de los paisajes, estos adoptan distintos criterios en función del objetivo perseguido: se habla así de "paisajes naturales", "paisajes transformados", "paisajes rurales", "paisajes urbanos", etc. Si se considera el grado de antropización, sin lugar a dudas los últimos son aquellos donde las modificaciones efectuadas por la actividad del hombre son más significativas y se caracterizan por poseer elevada heterogeneidade espacial. Sin embargo, estos paisajes no son, necesariamente, los únicos que han sido alterados en gran medida por las actividades humanas. (MAZZONI, 2014, p.58).

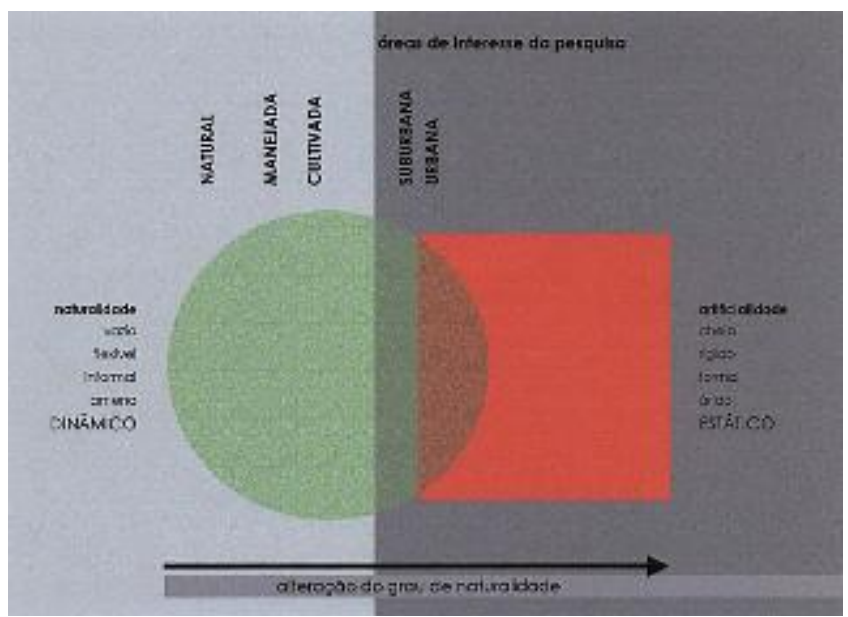

FIGURA 2 - Esquema das principais tipologias de Paisagem

Fonte: HARDT (2000, p. 18)

Assim, considerando genericamente a paisagem urbana como a visualização dos ecossistemas, envolvendo os sentidos da percepção mental, sensorial (principalmente as visuais) e sensações estáticas, há a necessidade de entendimento das formas classificatórias das paisagem, desde o que se pode perceber como natural, manejada, cultivada, suburbana e a urbana. Para que dessa forma, haja a efetiva compreensão da paisagem urbana, a qual é basicamente formada por: - espaço visual, enquanto composto por ambiente natural e ambiente construído, sendo o resultado das condições naturais e sociais; - mecanismos perceptuais, estes dependem da experiência humana, ou seja, ambiência pessoal e comportamento, condicionados pelos valores de condições de visibilidade, qualidade e fragilidade da paisagem, sendo respostas sensitivas e psicológica do observador, e, portanto, todos os elementos imbuídos de percepção estão relacionados com as condições de vida do observador, Hardt (2000).

\section{Paisagem urbana e suas contradições}

A concepção de paisagem urbana deve ser concebida conforme uma composição espacial subjulgada a valores e princípios filosóficos intrínsecos à sociedade à qual pertence.

Há uma crescente preocupação com a qualidade ambiental, a qual está relacionada com a construção de um ambiente ecologicamente equilibrado, sendo assim, todos os elementos da paisagem urbana são considerados e conciliados aos vários tipos de usos do solo e suas diversas atividades com a dinâmica natural dos seus elementos físicos. Portanto, analisar uma paisagem urbana é imprescindível, primeiro considerar o contexto 
social, econômico, ambiental e cultural, onde que é fundamentalmente importante compreender as relações e interações, já que, todas as atividades realizadas nessas paisagens, associadas ao inadequado planejamento e infraestrutura, podem influenciar na queda da qualidade do ambiente. E dessa forma, a qualidade ambiental, surge como fator preponderante em toda e qualquer análise das paisagens urbanas (LIMA, 2013).

Sabendo que as relações e contradições são produtos inerentes à paisagem urbana, pois, esta pode ser definida como uma unidade visível e invisível, caracterizada por fatores de ordem natural, social e também cultural, contendo, no entanto, espaços e tempos distintos (LIMA, 2013).

Entendendo que a paisagem urbana foi um dos fenômenos mais relevantes da história da humanidade, e é com o surgimento das cidades, que a raça humana encontrou um novo nicho, (BONAMETTI, 2010).

A evolução histórica da paisagem urbana e seus processos de intervenções, destaca-se claramente que sempre na sociedade procurou-se estabelecer o ideal de poder, e como resultado seus reflexos de padrões políticos, econômicos, estéticos e culturais. E "os contatos com a natureza, a tecnologia e o sistema de poder vigente tiveram importância fundamental na vida das civilizações, que construíram, com o passar das eras, uma relação peculiar com a paisagem urbana”. (BONAMETTI, 2010, p. 260).

Podemos entender que as relações entre os processos de urbanização e os sistemas natural e cultural passaram por diversos estágios ao longo dos períodos históricos, como impactos de maior ou menor significado, porém independente de sua dimensão de resultado fica claro suas interferências impressas em seu contexto histórico, desde a pré-história até a idade contemporânea, Hardt (2000).

Hardt (2000) interpreta Sutton \&Harmon (1977) argumentando que a expansão da população urbana mundial tem requerido intensivo controle ambiental, pois as intervenções do homem têm criado ambientes completamente novos. Diante disso, o ecossistema urbano constitui o ambiente onde o homem pode ex ercer seu poder de controle de forma efetiva. Pois, "os sistemas urbanos têm se tornado fonte de aumento de instabilidade na biosfera, afetando e sendo afetados por ela como um todo; o funcionamento de qualquer metrópole interdepende não apenas de ecossistemas locais, mas de toda a biosfera”. (HARDT, 2000, p. 29).

Salienta-se ainda, que a cidade pode ser interpretada como o supersistema dos sistemas natural e cultural urbanos (figura 3), e que nesse contexto é adicionada a experiência humana, (HARDT, 2000).

E conforme a figura 3, o ambiente total é composto por: ambiente natural, o qual é formado pelo subsistema físico (elementos abióticos) e biológico (produtores e consumidores) do sistema natural; ambiente construído, dotado do subsistema territorial (ou de ocupação - elementos abióticos) do sistema cultural; e ambiente socioeconômico, como sendo o subsistema social (ou de consumo - consumidores), econômico (ou de produção - produtores) e institucional (ou de gestão - elementos reguladores) (HARDT, 2000).

Entende-se que os elementos desencadeadores de maiores transformações na cidade, destacam-se a intensificação do uso e ocupação do solo e a acentuação do crescimento demográfico, e diante disso, os ecossistemas urbanos podem ser classificados como (figura 4): 


\section{OS DESAFIOS DA GEOGRAFIA FÍSICA NA FRONTEIRA DO CONHECIMENTO \\ Instituto de Geociências - Unicamp \\ Campinas - SP \\ 28 de Junho à 02 de Julho de 2017}

de Geografia Física

a) urbanização extensiva: reduzido grau de ocupação do solo e baixa densidade demográfica;

b) urbanizaçãosemi-intensiva: reduzido grau de ocupação do solo e média ou alta densidade demográfica, médio ou elevado grau de ocupação do solo e baixa densidade demográfica, ou médio grau de ocupação do solo e média densidade demográfica:

c) urbanização intensiva: elevado grau de ocupação do solo e alta densidade demográfica. (HARDT, 2000, p. 37-38).

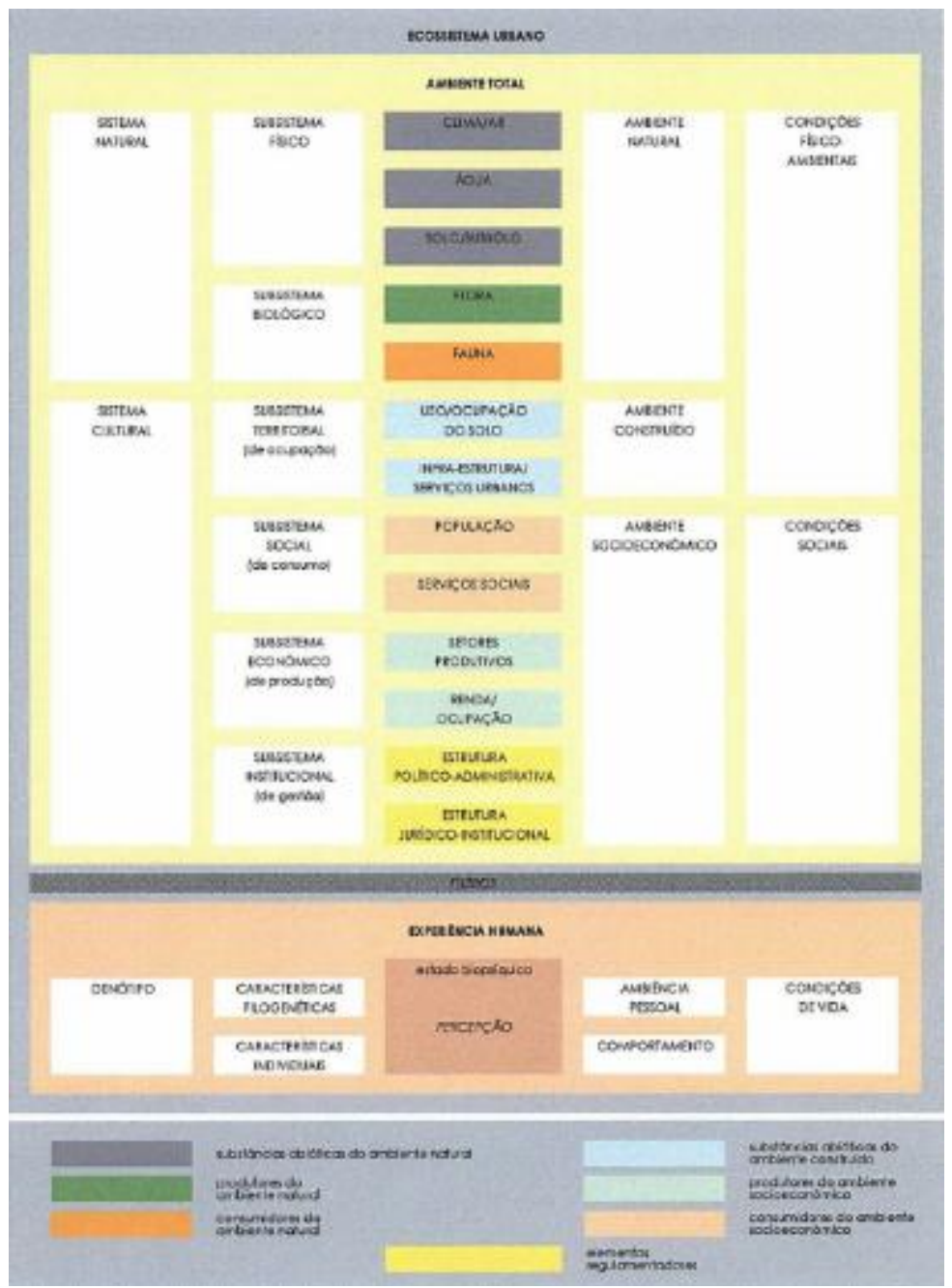

FIGURA 3 - Organograma dos componentes do ecossistema urbano.

Fonte: HARDT (2000, p. 32)

Na discussão de Hardt (2000) sobre a tipologia apresentada na figura 4, a cidade pode ser apresentada como um todo, ou mesmo, uma equivalente às áreas específicas. Portanto, nessa visão intra-urbana, a tipologia anterior pode ser genericamente associada às zonas urbanísticas características: residenciais, comerciais, de serviços, industriais etc.

A morfologia que significa morphê (grego)=figura+logia=estudo, ou seja, estudo das formas. Sendo assim, explica a cidade como fenômeno físico e construído se utiliza de dados econômicos, geográficos, históricos arquitetônicos etc., responsável então, para estudar a forma urbana.

A paisagem urbana é formada por elementos físicos e artificiais. Os elementos físicos estão relacionados ao sítio e o artificial às formas. (LIMA, 2013, p. 59). 


\section{OS DESAFIOS DA GEOGRAFIA FÍSICA NA FRONTEIRA DO CONHECIMENTO \\ Instituto de Geociências - Unicamp \\ Campinas - SP \\ 28 de Junho à 02 de Julho de 2017}

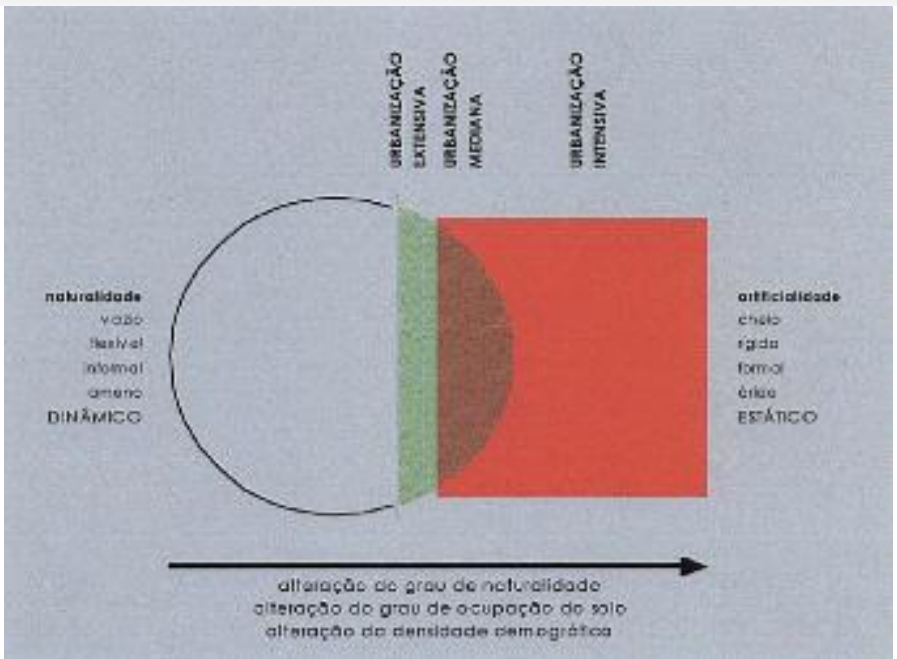

FIGURA 4 - Esquema de tipologia dos ecossistemas urbanos.

Fonte: HARDT (2000, p. 38)

Dentro da perspectiva da compreensão das relações imbuídas nas paisagens urbanas, esta, enquanto categoria de análise das relações sociedade/natureza pode ser entendida como ecossistema urbano, o qual possui necessidades biológicas, mas também culturais, econômicas, sociais, que possui a capacidade de liberar ou produzir fluxos de energias (LIMA, 2013).

Todo um complexo fluxo de matéria e energia, de origem natural e/ou produto da ação humana, interage permanentemente no contexto urbano e dinamizam as formas com que se manifestam os elementos da natureza e da sociedade na cidade, formando a materialidade urbana. (MENDONÇA, 2004, p. 199).

Nesse sentido as paisagens urbanas denunciam a degradação ambiental, em maior ou menor grau, pela própria organização econômica e social do espaço. "As cidades devolvem para a natureza seus resíduos, como dejetos domésticos e industriais, poluição, seja do ar, da água ou do solo, além dos problemas causados pela constante artificialização da natureza [...]" (LIMA, 2013, p. 64).

Por vezes, as paisagens urbanas observadas com ausência de vegetação nos espaços permeáveis das cidades,resultam problemas não somente de ordem da degradação do ambiente, mas também o desequilíbrio do volume das águas pluviais para menos ou para mais, neste último há agravantes no sentido de ocorrência de enchentes, inundações, processos erosivos, e, além disso, a ausência de áreas verdes influi diretamente no micro clima, conforto térmico e na dispersão de partículas suspensas no ar (LIMA, 2013).

Uma das principais mudanças na formação dos centros urbanos está relacionada à artificialização dessas paisagens que incluem um alto percentual de áreas impermeáveis e a ausência, em muitos casos, de vegetação ou aincorporação em locais inadequados e em pequenas quantidades.(LIMA, 2013, p. 67).

Contudo, a paisagem urbana é a expressão de uma mistura advinda da arte, ciência e acaso. É observado que na sua construção são recorrentes as renovações das morfologias antigas e a criação de novas que atendem aos novos estilos de vida impostos por cada momento histórico em consequência da manifestação do poder. Nesse ínterim "seus critérios de organização vão sendo constantemente questionados e modificados com a evolução e transformação da sociedade, das ciências, das técnicas e das diferentes formas de manifestações do poder", (BONAMETTI, 2010, p. 263). 
Monteiro (1993) diz que o urbanismo é, em seu significado mais concreto, mais uma das fases do processo desequilibrado de domínio do meio, que teve início com a descoberta do fogo, e que seguiu para o desenvolvimento da agricultura e teve seu desfecho na industrialização. "Mas ao mesmo tempo em que a industrialização corrói a cidade, a coloca num novo patamar, fazendo-a explodir [...]" e ainda continua, "a cidade leva tudo para ela e a explode numa dimensão nunca vista: junto à concentração urbana e ao êxodo rural se produz a extensão do tecido urbano e subordinação completa do agrário ao urbano". (SOBARZO, 2006, p. 59).

Nesse sentido, as condições de vida das populações desempenham importante papel na definição e compreensão dos problemas ambientais urbanos, revelando ao mesmo tempo, que os riscos ambientais urbanos destacam-se nas diferenciações de eventualidades e permanências, isto é, os citadinos estão expostos permanentemente aos riscos cotidianos, como por exemplo, incêndios, acidentes de trânsito, poluição etc.; e não são geralmente tomados em conta, ao passo que os eventos extremos são os considerados. (MENDONÇA, 2011).

E assim, pensando o clima como o nível de resolução geral do Sistema Climático e admitindo que o sistema global é formado por uma série de subsistemas integrados, acompanha a noção de co-participação do homem e da natureza no resultado final. "O sistema climático é, portanto, uma estrutura global, organizada e hierarquizada horizontalmente (na estrutura) e verticalmente (na função).” (MONTEIRO, 1993, p. 11).

Monteiro (1993) destaca que tal Sistema Climático, acredita-se estar formado por uma série de regras de funcionamento, e o clima global vai refletir as várias soluções que são adaptadas pelos níveis estruturais inferiores, ou seja, pelos subsistemas climáticos regionais e locais, para assim, filtrar, selecionar e conduzir toda e energia e matéria imbricada em toda essa relação.

Dessa forma, a construção da paisagem urbana resulta no Clima Urbano, este é percebido nas formas sensoriais e visuais dos observadores, isto é, os sistemas que o compreende e que retornam à paisagem urbana, como impactos pluviométricos, de temperaturas e de poluição. Assim, é possível compreender que a produção da paisagem urbana está com contradição à qualidade ambiental, visto que, é a responsável pela ocorrência do clima urbano, o qual, tem grande potencial depredativo à sociedade urbana em variadas escalas.

\section{Justificativa e área de pesquisa}

Os fenômenos naturais relacionados e interconectos ao clima e às condições de tempo, quando manifestados principalmente como eventos extremos, resultam inúmeros problemas nas sociedades urbanizadas, além disso, muitos desses eventos classificados como catástrofes, repercutem irredutivelmente de forma negativa na vida de parte da sociedade, Zanella et al. (2009).

Sublinha-se que as graves consequências resultantes da desenfreada busca pelo progresso, causa o distanciamento do homem de seu suporte ambiental. Então as cidades, se destacam como projeções 
integralmente artificiais no espaço das novas necessidades de troca de excedentes, os quais permitiram que o homem pudesse ter controle do seu habitat, e tal controle promoveu o sentimento de irreverência quando se aponta para o Meio Ambiente. E "intuitivamente, por formação e porque sempre fomos mais um dos operadores de um ecossistema urbano, apercebemo-nos das várias nuances que ele tem sofrido nas últimas décadas". (MONTEIRO, 1993, p. 03).

No que se concerne às concepções de cidades de médio porte, conforme o censo demográfico de 2010 houve a reconcentração de população urbana brasileira nos grandes centros do país, e, dessa mesma forma, é apontado que também, houve um aumento e dispersão de cidades de médio porte no território brasileiro (STAMM et al, 2013).

Sabendo que as cidades dentro de determinadas áreas podem ser classificadas de forma hierárquica, normalmente, conforme suas funções econômicas, e, suas faixas hierárquicas geralmente são expressas por uma divisão de classes de tamanhos da população (STAMM et al., 2013).

As cidades de menor porte são tidas apenas como um centro mediador do comércio local com as regiões. As cidades de médio porte, além das funções das cidades de menor porte, apresentam um maior peso econômico e assumem a função de suprir as demandas dos produtos que não são produzidos nos centros de menor porte. As cidades de grande porte (ou metropolitanas) se distinguem pelo maior volume populacional, por serem polarizadoras de centros menores, e caracterizam-se por apresentar uma mancha de ocupação derivada de conurbação (CHRISTALLER, 1966; GEDDES, 1994; IPEA et al., 1999). (STAMM et al., 2013, p. 252-253).

Portanto, considerando todos os atributos que definem as cidades de médio porte, estas se enquadram nas cidades de população entre 50 mil a 250 mil habitantes. Contudo, "pode-se inferir que uma cidade de porte médio deve dar suporte a uma quantidade importante de atividades e serviços que exigem para existir uma população não inferior a 100 mil habitantes". (STAMM et al., 2013, p. 254).

Os estudos para se analisar o ambiente urbano com seus respectivos reflexos na distribuição e espacialização das chuvas e da temperatura do ar, bem como do comportamento de emissões e concentrações de poluentes na atmosfera urbana, é que a Teoria do Clima Urbano, elaborada por Carlos Augusto de Figueiredo Monteiro em 1976, considera-se fundamental para entendimento das relações homem/natureza nos espaços urbanizados.

Monteiro (1976) calca as bases teóricas do Sistema Clima Urbano (SCU) na Teoria Geral dos Sistemas (TGS), onde que a transformação do conhecimento é o resultado da nossa capacidade de resolver problemas, e sob o ponto de vista do clima urbano, constitui-se como uma questão de sobrevivência humana, Santos (2014).

Todos os fatos da observação do clima da cidade têm implicação determinante em consideráveis transformações, como as ilhas de calor e também a poluição do ar, sendo estes indubitavelmente as demonstrações mais eloquentes. E, portanto, nos termos mais simples da TGS, o SCU, considerando-o um sistema aberto, Monteiro (1976). 
Considerando que os insumos de energia que alimenta o SCU, são aqueles conduzidos diretamente à atmosfera que envolve a cidade, oriundos das fontes primárias de energia da Terra, ou seja, o Sol; sabendo que, como elemento do sistema, o homem, isto é, a comunidade social urbana, tem direta e indireta importância na influência da estrutura interna do sistema, devido ao seu grande potencial de desempenho na transformação da energia que se adentrou e pelas modificações na estrutura urbana, Monteiro (1976).

Para Monteiro (1976) o SCU liga-se à percepção humana, e assim, subdivide o sistema em canais de percepção, os quais estão associados intimamente aos principais níveis de resolução do sistema, separando, portanto, os grandes conjuntos dentro do universo climático. O próprio autor diz que essa separação, é de certa forma até arbitrária, porém, não será minimizada as análises do clima e seus atributos elementares, nem de redução ao nível de elementos, mas sim, da aglutinação em conjuntos, mantendo a associação intrinsecamente atmosférica, ou seja, composição, comportamento e produção meteórica, reportando-se à percepção sensorial e comportamental do homem que habita a cidade.

No Subsistema Termodinâmico, relacionado ao Canal I Conforto Térmico da teoria sistêmica de Monteiro (1976), referenda as discussões e reflexões acerca das formas de ocupação do espaço urbano, com seus diferentes tipos de construções, de ordenamento e parcelamento dos solos, e consequentemente os distintos microclimas formados dentro do ambiente urbano. E dessa forma a qualidade de vida das dos habitantes das cidades estão diretamente correlacionados às construções e ordenamentos feitos pelas mãos humanas, onde que, as disparidades e problemas sociais e ambientais são expressivamente consideráveis e "no que concerne ao conforto térmico, é comprovado pelo índice de desconforto térmico e pelo Subsistema Termodinâmico o quanto pode interferir na saúde humana - em escalas coletiva e individual - e no desempenho de atividades cotidianas". (GOMES, 2012, p. 08).

Para Monteiro (1976) o canal I, engloba as componentes termodinâmicas que, em suas relações diversas, vem a se expressar por meio do calor, ventilação e umidade. Sendo estes um filtro perceptivo bastante significativo, que afeta a todos de forma permanente e, consequentemente é um assunto de investigação de importância crescente. "A geração da ilha de calor é suficiente para desencadear uma ventilação urbana, que se alterna com aquela local do quadro geoecológico e aquela mais ampla da circulação regional". (MONTEIRO, 1796, p. 126).

Já os estudos pertinentes às poluições enquadram-se no subsistema Físico-Químico do Canal II Qualidade do ar. Pois os impactos na saúde, e o agravamento ou desenvolvimento de algumas doenças são causadas pelo grau da qualidade do ar como reflexos das atividades intra-urbanas.

Devendo compartilhar da ideia de S. BOYDEN que "[...] a cidade é um gigantesco animal móvel, consumidor de vastas quantidades de oxigénio, água e matéria orgânica e excretor de dióxido de carbono, dióxido de enxofre, fumos, vapor de água e desperdícios orgânicos [...]”. (BOYDEN, 1981, p. 18 apud MONTEIRO, 1993, p. 05). E valendo também das mesmas intenções de Monteiro (1993), essa pesquisa se utilizará da poluição atmosférica como um indicador do ritmo de interferência das atividades funcionais 


\section{OS DESAFIOS DA GEOGRAFIA FÍSICA NA FRONTEIRA DO CONHECIMENTO \\ Instituto de Geociências - Unicamp \\ Campinas - SP \\ 28 de Junho à 02 de Julho de 2017}

urbanas no clima da área, e diagnosticar as representações de concentração e dispersão dos poluentes para a atmosfera das cidades.

Para Monteiro (1976) a Qualidade do Ar enquanto canal de percepção, aponta a poluição como um dos males do século, e talvez é aquele, por seus efeitos mais dramáticos, e que consequentemente atraia mais a atenção da sociedade. Existem outros tipos de poluição, como da água e dos solos, porém, a do ar é uma das mais decisivas na identificação da qualidade do ambiente urbano, pois "[...] é nas concentrações urbanas, graças à circulação de veículos à auto-combustão, à concentração industrial e a outras formas de produção que se contamina a atmosfera". (MONTEIRO, 1976, p. 133).

E por último, o Subsistema Hidrometeórico, ligado ao Canal III Impacto Meteórico, aludi procedimentos de investigação e discussão no âmbito dos impactos das precipitações no ambiente urbano. As consequências negativas visualizadas na malha urbana das cidades podem ser causadas por falta de planejamentos da infraestrutura urbana, por ocupações irregulares, como ocupação das encostas dos morros, dos córregos e rios, ou até mesmo pelo crescimento urbano desordenado.

As considerações acerca do canal III, Monteiro (1976) aponta que estão grupadas nesse canal, todas aquelas formas meteóricas hídricas, como a chuva, a neve, e nevoeiros; as mecânicas, por exemplo; e as elétricas provenientes de tempestades; todas essas assumindo eventualmente, manifestações de grande intensidade, tem capacidade de provocar impactos negativos na vida da cidade, de forma a perturbá-la ou mesmo desorganizando-a em sua circulação de serviços. "A idéia de impacto pressupõe conseqüências calamitosas, atacando a integridade da cidade como artefato físico e perturbando, sensivelmente, as formas de circulação e comunicação internas e de ligação externa". (MONTEIRO, 1976, p. 136).

Justifica-se, portanto, que esse projeto de pesquisa, tem por intuito, a partir do referencial teórico baseado na teoria sistêmica (SCU) de Monteiro (1976), a pretensão de estudo sistêmico do Clima Urbano da Região Centro-Oeste, especificamente, a cidade de Dourados no estado de Mato Grosso do Sul; e, a cidade de Rio Verde no estado de Goiás, conforme mapa 1. E assim, dialogar com os resultados do clima urbano dessas cidades com os aportes das Ciências Geográficas e da Climatologia Geográfica. 

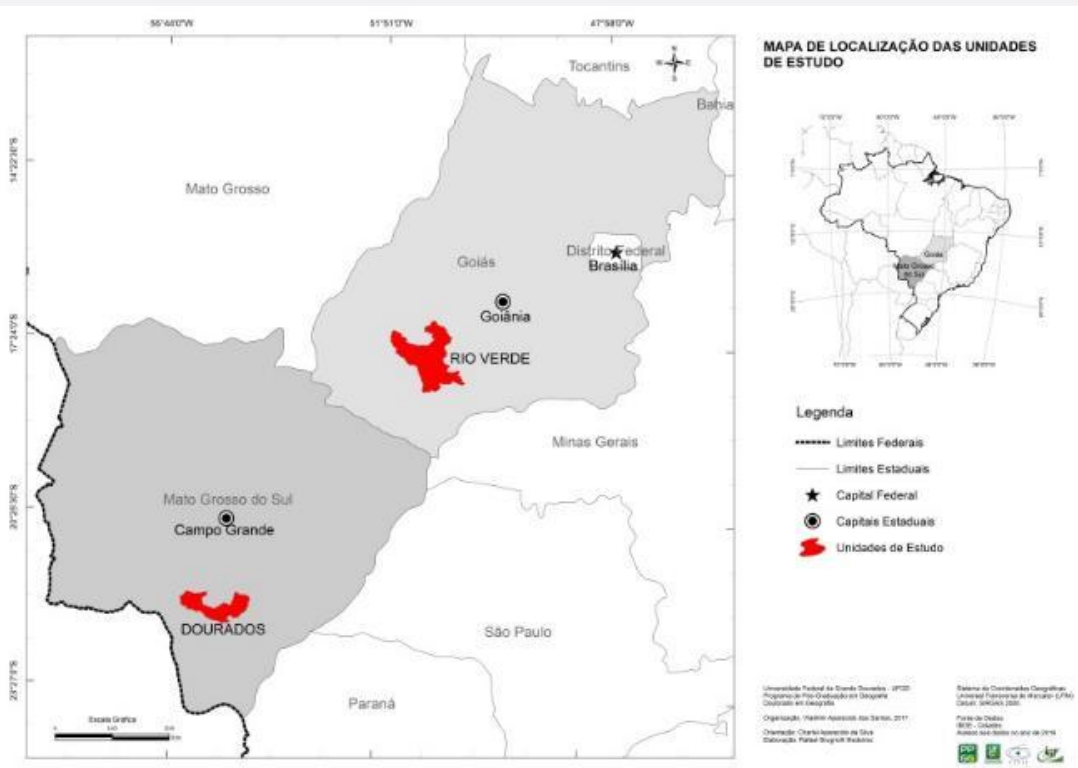

MAPA 1 - Espacialização das áreas de estudo no Centro-Oeste.

Por fim, será de fato proposto uma hipótese no âmbito dos testes, averiguações, investigação e categorização com intuito de estabelecer a compreensão dos ambientes urbanos das cidades citadas da Região CentroOeste, do ponto de vista da escala do clima regional e local, que compreendem-se justamente pelas influências e correlações dos elementos climáticos com o metabolismo urbano, sendo que a partir dessa consideração é que estão imbricadas todas as relações e construções sociais pautadas na teoria do Clima Urbano das cidades, com subsídio teórico do SCU enquanto admitido como sistema aberto, o qual tem por base teórica a TGS.

\section{Considerações finais}

Os conceitos inerentes à paisagem, e seus desdobramentos de paisagem urbana, se farão de extrema importância para dar sustentação teórica a esta pesquisa, no que se refere aos resultados e transformações produzidas no interior do ambiente urbano das cidades de médio porte da Região Centro-Oeste brasileira. Além de proporcionar discussões acerca da gestão e planejamento do território.

Espera-se que a partir dos estudos relacionados ao monitoramento e análise diante da teoria do SCU desenvolvido por Monteiro (1976), venha a contribuir na compreensão e entendimento da dinâmica circulatória urbana e seus produtos relacionados com a qualidade do ar, conforto térmico e o impacto meteórico das áreas urbanas de cidades médias da região Centro-Oeste, a saber, as cidades de Dourados/MS e Rio Verde/GO. Tendo em vista toda sua dinâmica econômica diante do intenso processo de crescimento agroindustrial e frota veicular das cidades da região.

Os avanços que serão adquiridos com o fim da pesquisa estão imersos de forma imprescindível, a médio e longo prazo, para novas proposições metodológicas de avaliação do impacto ambiental urbano e ao mesmo tempo servir como material metodológico para futuros trabalhos para região Centro-Oeste e Brasil. Tendo em vista que, os resultados balizarão novas pesquisas de qualidade ambiental das cidades, pois o ambiente é um bem comum, sem sessar, portanto, o contínuo crescimento urbano e da agroindústria. 
Entende-se como produto final, não somente a discussão diagnóstica do conforto térmico, impactos hidrometeóricos, padrão de urbanização dos agrupamentos sociais, mas também, o entendimento e reflexão das propriedades físico-químicas da poluição atmosférica do ambiente urbano, padrão de qualidade do ar e os possíveis reflexos negativos sobre saúde humana.

Os resultados do SCU das duas cidades, e nessa conjuntura, o MS terá grande avanço em pesquisas de cunho termodinâmico, físico-químico e de impactos meteóricos de toda região centro-oeste, podendo por fim, estabelecer afirmativamente seu enorme potencial de pesquisa científica, desenvolvimento metodológico e de grande capital intelectual e humano.

Sabendo que há grande esforço ao desenvolvimento econômico do Brasil, em especial às cidades em questão, é, portanto, observado em termos predatórios, os reflexos do imediatismo econômico. Com isso, o crescimento das cidades de médio porte, e seu acelerado processo de expansão da malha urbana, aponta para a relevância dos estudos do Clima Urbano, tais interesses podem ser dirigidos como de importância nas escalas locais, regionais, nacionais e globais, visto que, o estágio da velocidade de produção é proporcional a depredação do ambiente, seja por impactos relativos aos subsistemas hidrometeórico, termodinâmico e/ou físico-químico.

É nesse sentido, movido pela preocupação e em caráter inédito, que está sendo desenvolvido métodos de avaliação da paisagem urbana e de clima urbano de cidades de médio porte do Centro-Oeste em nível de doutoramento, pelo Laboratório de Geografia Física - LGF, no Programa de Pós-Graduação em Geografia PPGG da Universidade Federal da Grande Dourados - UFGD; com o propósito de estabelecer de forma classificatória as condições dos canais de percepção dos impactos meteóricos, conforto térmico e da qualidade do ar dos ambientes urbanos das cidade supracitadas.

\section{Bibliografia}

BONAMETTI, J. H. A paisagem urbana como produto do poder. Revista Brasileira de Gestão Urbana (BrazilianJournalofUrban Management), v. 2, n. 2, p. 259-273, jul./dez. 2010.

HARDT, L. P. A. Subsídios à Gestão da Qualidade da Paisagem Urbana: Aplicação a Curitiba- PR. Tese de Doutorado em Engenharia Florestal. Curitiba, PR: UFPR, 2000.

FERREIRA, A. B. H. Novo dicionário da língua portuguesa. 2. ed. Rio de Janeiro : Nova Fronteira, 1986.

FERREIRA, C. C. proposta de zoneamento ambiental das paisagens para o alto curso da bacia hidrográfica do Rio Sucuriú, Mato Grosso Do Sul-Brasil.Tese de Doutorado em Geografia. Presidente Prudente, SP: UNESP, 2016.

GOMES, S. T. Clima urbano de Dourados (MS): uma análise a partir do processo de urbanização.2012. Dissertação (Mestrado em Geografia) - Universidade Federal da Grande Dourados-UFGD, Dourados, MS, 2012.

LIMA, V. A Sociedade e a Natureza na paisagem urbana: análise de indicadores para avaliar a qualidade ambiental.Tese de DoutoradoemGeografia. Presidente Prudente, SP: UNESP, 2013.

MAZZONI, E. Unidades de paisaje como base para la organización y gestión territorial.EstudiosSocioterritoriales. Revista de Geografía. n 16, vol. 2, jul-dic, pág. 51-81, 2014.

MENDONÇA, F. S.A.U. O Sistema Socioambiental Urbano: uma abordagem dos problemas socioambientais da cidade. In: MENDONÇA, Francisco (org.) Impactos Socioambientais urbanos. Curitiba: Ed. UFPR, p. 185-208, 2004.

A geografia (física) brasileira e a cidade no início do século XXI: algumas contingencias e desafios. In: FIGUEIRÓ, A. S. e FOLETO, E. (org.). Diálogos em geografia física. Santa Maria: UFSM, 2011, 208p. 


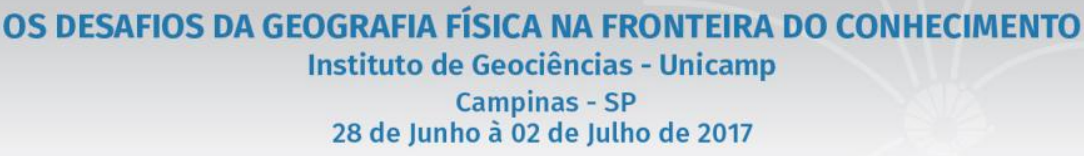

MONTEIRO, C. A. F. Teoria e clima urbano. São Paulo, USP/FFLCH, Tese (Livre-Docência), 1976.

MONTEIRO, A. Clima Urbano do Porto: Contribuição para a definição das estratégias de planejamento e ordenamento do território. Tese de Doutorado. Universidade do Porto - Portugal, 1993.

SALINAS, E. El Ordenamiento Territorial como Instrumento de la Planificación y Gestión Ambiental.

SANTOS, V. A. A qualidade do ar de Dourados (MS): uma contribuição aos estudos de Clima Urbano com foco no subsistema físico-químico. Universidade Federal da Grande Dourados. Mato Grosso do Sul: UFGD. Dissertação (Mestrado), 2014.

SOBARZO, O.O urbano e o rural em Henri Lefebvre. In:SPOSITO, Maria E. B., WHITACKER, Arthur M. Cidade e campo: relações e contradições entre urbano e rural. São Paulo: Expressão popular, p. 53-64, 2006.

STAMM, C.; STADUTO, J. A. R.; LIMA J. F.; WADI, Y. M. A população urbana e a difusão das cidades de porte médio no Brasil. Revista Interações, Campo Grande, v. 14, n. 2, p. 251-265, jul./dez. 2013.

ZANELlA, M. E.; SALES, M. C. L.; ABREU; N. J. A. Análise das precipitações diárias intensas e impactos gerados em Fortaleza, CE. Revista Geoups - Espaço e Tempo, São Paulo, nº 25, p. 53-68, 2009. 